Please do not remove this page

RMIT

UNIVERSITY

\title{
Case study and back analysis of a residential building damaged by expansive soils
}

Li, Jie; Cameron, Donald; Ren, Gang

https://researchrepository.rmit.edu.au/esploro/outputs/9921859761301341/filesAndLinks?institution=61RMIT_INST\&index=null

Li, J., Cameron, D., \& Ren, G. (2014). Case study and back analysis of a residential building damaged by expansive soils. Computers and Geotechnics, 56, 89-99. https://doi.org/10.1016/j.compgeo.2013.11.005 Document Version: Accepted Manuscript

Published Version: https://doi.org/10.1016/j.compgeo.2013.11.005

Repository homepage: https://researchrepository.rmit.edu.au (c) 2013 Elsevier Ltd. All rights reserved.

Downloaded On 2023/04/26 22:40:42 +1000 
Thank you for downloading this document from the RMIT Research Repository.

The RMIT Research Repository is an open access database showcasing the research outputs of RMIT University researchers.

RMIT Research Repository: http://researchbank.rmit.edu.au/

\section{Citation:}

Li, J, Cameron, D and Ren, G 2013, 'Case study and back analysis of a residential building damaged by expansive soils', Computers and Geotechnics, vol. 56, pp. 89-99.

See this record in the RMIT Research Repository at:

http://researchbank.rmit.edu.au/view/rmit:22756

Version: Accepted Manuscript

Copyright Statement: (c) 2013 Elsevier Ltd. All rights reserved.

Link to Published Version:

http://www.researchgate.net/publication/259512821_Case_study_and_back_analysis_of_a_residenti al_building_damaged_by_expansive_soils

\section{PLEASE DO NOT REMOVE THIS PAGE}




\title{
Case Study and Back Analysis of a Residential Building Damaged by Expansive Soils
}

\author{
Jie $\mathrm{Li}^{1}$, Donald A. Cameron ${ }^{2}$ and Gang $\operatorname{Ren}^{1}$
}

${ }^{1}$ Senior Lecturer, School of Civil, Environmental and Chemical Engineering, RMIT University, GPO Box 2476, Melbourne 3001, Australia.

${ }^{2}$ Senior Lecturer, School of Natural and Built Environments, University of South Australia, Mawson Lakes, SA 5095, Australia.

\section{Corresponding Author:}

Dr. Jie Li

Senior Lecturer

School of Civil, Environmental and Chemical Engineering

RMIT University, GPO Box 2476

Melbourne 3001, Australia

Tel: $\quad+61399253554$

Fax: $\quad$ +61396390138

e-mail: $\quad$ jie.li@rmit.edu.au 


\title{
Case Study and Back Analysis of a Residential Building Damaged by Expansive Soils
}

J. Li, D. A. Cameron and G. Ren

\begin{abstract}
This paper presents a case study of a residential house damaged by expansive soils. The field investigation revealed that the damage was most likely caused by excessive lawn watering and leaks of sewer pipe and/or stormwater pipe, which resulted in non-uniform soil moisture conditions. Three-dimensional back analysis of this distressed structure indicated that stresses were most critical at a re-entrant corner and that steel reinforcing bars in the beam in this area had yielded. The results of the back analysis also indicated that a stronger footing was required to limit differential deflection to an acceptable level and reduce stress in the footing. The case study has clearly shown that a leaking underground water pipe and/or excessive watering of a garden could cause more severe distortion to a single storey masonry veneer house than could be expected from seasonal moisture change and the deeper moisture redistribution caused by the imposition of the house on seasonally dry reactive soil. Moreover it has been demonstrated that it would be extremely costly to design a footing for extreme, or abnormal, moisture changes.
\end{abstract}

\section{Key Words}

Expansive soils, case study, back analysis, finite element, residential footing 


\section{Introduction}

Expansive or reactive soil is any soil composed predominantly of clay, which undergoes appreciable volume change in response to changes in soil moisture content. This volume change occurs as swelling upon wetting, and shrinkage upon drying. Buildings constructed on expansive soils are frequently subjected to severe movement arising from non-uniform soil moisture changes, with consequent cracking and damage related to the distortion. These moisture changes may be induced by rainfall and evaporation, garden watering, leaking water pipes, or tree root activity.

Damage to lightly loaded structures founded on expansive soils has been widely reported in many countries such as Australia, China, India, Israel, South Africa, the United Kingdom and the United States of America. In the United States alone, total damage due to expansive soil is estimated to cost \$US15 billion per year (Jones and Jefferson 2012), more than twice the damage from floods, hurricanes, tornadoes, and earthquakes combined. The American Society of Civil Engineers estimates that one in four homes have some damage caused by expansive soils (Jones and Jefferson 2012). The annual cost of expansive soil damage in China is estimated to be approximately \$US15 billion (Miao et al 2012). The Association of British Insurers has estimated that the average cost associated with damage due to expansive soil is over $£ 400$ million a year, making it the most damaging geohazard in the UK today (Jones and Jefferson 2012). The problems are particularly significant in Australia as approximately $20 \%$ of Australia is covered with expansive soils (Cameron et al. 1987; Walsh and Cameron 1997) and six out of eight of Australia's largest cities are significantly affected by expansive soils (Fityus et al. 2004; Delaney et al. 2005). Before a national standard was introduced for site classification and design of footings, it was reported by Considine (1984) more than 50000 
houses cracked each year in Australia, which accounted for approximately $80 \%$ of all housing insurance claims.

Over the last 40 years or so, much effort has been devoted to methods of analysing and designing structural footing systems on expansive soils. Since 1986, Australian footing design and construction practices have been guided by a national standard. The current Australian Standard for residential slabs and footings is the 2011 edition (AS2870, 2011). Common to the three versions of the Standard, sites are classified according to soil profile and regional climate influence on soil moisture state. Once a characteristic site surface movement has been estimated for a site and the type of house construction is known, a raft footing can be designed, usually based on two-dimensional approximations of true slab behaviour. Flexural strength, structural stiffness and section ductility are appraised so that the slab will keep differential deflections across the floor within tolerable limits. Section ductility is an important consideration to ensure that if ground movements are greater than anticipated, the reinforcing steel will not yield readily, and there remains the possibility that action may be taken to correct the cause of movement without the need to re-construct the building.

The Australian Residential Slabs and Footings Standard AS2870 provides simple and efficient design procedures, which assume that the moisture condition around the buildings will remain within reasonable limits. This means that owners should be aware of the need to make sure extreme soil moisture changes are avoided over the life of the house; maintenance of site drainage and prompt repair of leaking pipes are two actions which will help to achieve this aim. 
There are a number of cases of residential structures which have experienced significant cracking, despite the design of the footing systems conforming to the Australia Standard for residential footing design (Walsh and Cameron 1997; Li and Cameron 2002). In December 2011, the Housing Industry Association (HIA) estimated that more than 1000 new houses in the Western suburbs of Melbourne were damaged due to soil heave (The Age, 2011). These new houses have all been built according to Australian Standards and the Building Code. There are many different factors to consider in assessing damage to residential building constructed on expansive soils, which include the adequacy of the site investigation, the scope of the design and inherent underlying assumptions, construction practices and post construction site maintenance. In order to obtain a better understanding of the problem and to improve the current practice, more research is needed to quantify the impact of these factors on the performance of residential footings.

It is the authors' belief that improvements of current design approach can be achieved by case studies of the performance of footings on expansive soils. In this study, the field investigation and back analysis of a residential building damaged by expansive soils were carried out. The purposes of this case study were: (a) to determine the causes of deformation and cracking, (b) to estimate the stress level in the deformed slab footing, (c) to estimate the soil mound shape underlying the footing, and (d) to find out what footing design could cope with the estimated ground movement. The last point is contrary to a basic philosophy of the existing Standard, but may serve to reinforce the potential waste of resources trying to design all houses for extreme moisture events. This paper presents the results of the case study.

\section{Description of Case Study}


The case study concerned a single storey, articulated masonry veneer dwelling, which was constructed in March 1992 (at the end of the dry season) in a northern suburb of Adelaide, Australia. The site was approximately $32 \mathrm{~m}$ long and $20 \mathrm{~m}$ wide and had a slight fall of approximately $2 \%$ towards the South (Figure 1). Before construction, three boreholes were drilled to a depth of approximately $3 \mathrm{~m}$ at the site to estimate the shrinkage indices of the underlying soil profile using a visual-tactile method (Jaksa et al. 1997). The classification of the site for potential ground movement following the Australian Standard, AS2870 was Class E (i.e., extremely reactive; refer Table 1). Site classification is based on $y_{s}$, the predicted design site surface movement, over the life of the house, which is based on design soil suction change profiles for different climatic regions of Australia. The value of $y_{s}$ is determined by the following expression:

$$
y_{s}=\frac{1}{100} \int_{0}^{H} I_{p t} \Delta u d h
$$

where, $I_{p t}$ is the instability index of the soil, which is defined as the percent vertical strain per unit change in suction considering possible lateral restraint, $\Delta \mathrm{u}$ is the change in suction, in $\mathrm{pF}$ units in the soil layer under consideration, $d h$ is the thickness of the soil layer and $H$ is the design depth of suction change.

The stiffened raft slab was designed using the AS2870 recommended method, which generates empirically-based ground distortions or mound shapes from the design site surface movement. Two basic mound shapes are designed for: the short-term edge wetting distortion or "edge heave" mound, and the longer term central swelling and seasonal edge drying and distortion, or "centre" heave. The design then proceeds to limit footing deflections to levels tolerable for the supported building, by adding stiffening beams of sufficient depth and with adequate reinforcement. Interaction between the loaded footing and the soil is considered. 
Routine design however is based on simplified 2D analysis. In particular, the slab plan must be divided into fully overlapping rectangles, each rectangle being designed for centre heave and edge heave cylindrical mounds in both the short and long directions. One rectangle will dictate beam sizes for the whole slab.

For this case study, the footing layout is shown in Figure 1. The external beams were $300 \mathrm{~mm}$ wide by $950 \mathrm{~mm}$ deep, reinforced with $8 / \mathrm{Y} 16$ bars, four at the top and four at the bottom. The internal beams were $250 \mathrm{~mm}$ wide by $950 \mathrm{~mm}$ deep, reinforced with 6/Y16 bars, three at the top and three at the bottom. A Y16 bar refers to a $16 \mathrm{~mm}$ nominal diameter deformed bar of yield strength, $400 \mathrm{MPa}$. The slab was $100 \mathrm{~mm}$ thick and was reinforced with F62 mesh placed $25 \mathrm{~mm}$ from the top surface of the slab. F62 refers to plain hard drawn steel fabric, of 6 $\mathrm{mm}$ nominal diameter and spaced at $200 \mathrm{~mm}$ centres in each direction, and having a yield strength of $450 \mathrm{MPa}$.

\section{Post Construction Site Investigation}

After six years, the owner reported that the building was cracking. A site investigation was carried out by the authors in February (during the seasonally dry period in Adelaide, South Australia), to examine the cause of damage to the building. The investigation consisted of the following:

1) A visual inspection of external walls and all internal areas of the building;

2) Recording magnitude and location of cracking in wall, floor and ceiling;

3) Examination of the beam depth, slab thickness and the properties of concrete;

4) A level survey of the floor surface;

5) Borehole used for evaluation of the physical properties and engineering characteristics of the subsurface soils. 
The site inspection indicated that sewer pipe leaking had occurred at the front of the house, as well as stormwater pipe leaking at the back of bedroom 4 (Figure 1). The inspection revealed there was a large well-watered lawn in the backyard, which sloped gently down towards the building. Water was observed ponding at the back of the building adjacent to the footing (see Figure 1). Four small native shrubs were planted at the front of the property, approximately 5 $\mathrm{m}$ away from the building and adjacent to the footpath. The lawn in the front yard was well maintained as well. Damage to the house superstructure consisted of severe ceiling cracking (4-20 mm) in the family area (Figures 2$)$, and severe internal wall cracking $(3-16 \mathrm{~mm})$ in the dining room and lounge (Figures 3), moderate external wall cracking (2-3 mm) under the window of bedroom 2 (Figure 4), distortion of the cornice in the laundry (Figure 5), and a slope on the floors in most rooms. The floor of the house was distorted into a complex pattern, involving both bending and twisting.

Three boreholes were drilled to approximately $4 \mathrm{~m}$ deep to evaluate the soil profile and the level of reactivity of soil types within the profile. The location of boreholes is shown in Figure 1. Groundwater was not found in the soil borings. The geotechnical profile for soil found in BH1 is shown in Figure 6. The soil profile across the site was relatively uniform and the soil profile can be described generally as $150 \mathrm{~mm}$ of sandy clay topsoil underlain by very high plasticity clay to about $1.25 \mathrm{~m}$ then high plasticity clay to a depth of approximately $4 \mathrm{~m}$. Shrink-swell tests (Fityus, Cameron and Walsh, 2005) were conducted in accordance with AS1289.7.1.1 (1992) and the results are presented in Figure 6. It should be noted that a shrinkage index of $4 \% / \mathrm{pF}$ would be regarded as a highly expansive soil, $6 \% / \mathrm{pF}$ very highly expansive and $8 \% / \mathrm{pF}$, an extremely expansive soil. Site classification (Table 1) requires recognition of the soil profile and the distribution of soil reactivity with depth to enable an 
estimate of the potential ground movement for the site ("site reactivity") under normal moisture conditions. This estimate of ground movement is then used to classify the site.

Figure 6 also shows Atterberg limits and the soil swelling pressures obtained from the oedometer swell-pressure tests. Swell pressure testing consisted of loading back a swollen soil to its original height. The swell pressures were modest as the soil from $\mathrm{BH} 1$ was relatively wet, as is discussed later.

A level survey was performed by the authors around the perimeter and the interior of the house to determine the general pattern of the movement. Relative movement of the slab can be inferred from these contours assuming the slab was poured with a level surface. A total of 85 measurements were taken. Contours showing relative vertical movement on an approximately $1.5 \mathrm{~m}$ grid are plotted in Figure 7 . The contour plot indicated that a severe edge heave occurred in the long span. The maximum vertical differential movement of the raft slab footing was $100 \mathrm{~mm}$, which was well above the expected ground movement for this site and difficult for the building to deal with.

The measured level differences along the re-entrant corner are plotted in Figure 8. The second author found it necessary to extend distortion patterns around corners to better understand the causes of masonry wall cracking (Cameron and Walsh, 1981). The differential deflection to length ratio was $1 / 273$, exceeding the recommended maximum limit of $1 / 400$ for articulated masonry veneer construction (AS2870 2011). The deflection ratio was derived as shown in Figure 8 , and it did not include tilting movements, but rather considered only distortional movement. The maximum differential deflection along segments $\mathrm{AB}$ and $\mathrm{BC}$ was $85 \mathrm{~mm}$ and 
$46 \mathrm{~mm}$ respectively, much higher than the maximum allowable limit of $30 \mathrm{~mm}$ for articulated masonry veneer (AS 2870, 2011).

The site investigation revealed that the main cause of house distortion may be attributed to leaks of both sewer pipe and stormwater pipe, and excessive watering of the lawn and garden areas, which resulted in non-uniform soil moisture conditions. The locations of the leaks and water ponding due to excessive watering are shown in Figures 1 and 7.

The initial suction state of the soil at this site was not determined as it is not a routine site investigation procedure for house construction. During the site investigation, three boreholes were drilled around the house for determination of soil current suction profiles. The soil samples were sealed and labelled on extraction from the borehole and then transported to the laboratory. Suction tests were carried out in accordance with AS1289.2.2.1 (1992). Prior to testing, samples were stored in a constant temperature room at $20^{\circ} \mathrm{C}$ and $50 \%$ relative humidity for at least 24 hours so that thermal equilibrium between the soil and the sample chamber could be achieved. Soil suctions were measured in this same room using a Wescor HR-33T dew-point microvoltmeter with C52 sample chambers. The equipment functions as a dewpoint hygrometer and has a working range of $3.2 \mathrm{pF}(160 \mathrm{kPa})$ to $4.8 \mathrm{pF}(6310 \mathrm{kPa})$. Wet soils are less reliably measured with this equipment.

Each reported suction value was taken as the average value of at least three sub-samples. Figure 9 shows the soil suction profiles and the locations of boreholes. The effect of the water leaking from the stormwater and sewer pipes is clearly evident in the suction profiles of Figure 9. Suction profiles near the leaking pipes indicated unusually low suctions, or wet soil, 
over the full depth of sampling. At the re-entrant corner of the house (borehole 2), the soil was much drier.

\section{The Back Analysis Method}

It was recognised that a suitable method of back analysis had to utilise the information available from a cracked house investigation. In routine practice in Australia, three boreholes are usually drilled for each site prior to the construction of the house. These boreholes are used to estimate the characteristic surface movement, $\mathrm{y}_{\mathrm{s}}$, at the site, and the highest value of $\mathrm{y}_{\mathrm{s}}$ is adopted for design. Generally the soil is not tested for either suction or reactivity. Therefore the suction-flow-soil-footing interaction model cannot be applied here since the soil suction changes under the footing are unknown. This model was used to investigate the effects of a leaking underground water pipe on a stiffened concrete slab on expansive soils (Li 2006).

The proposed back analysis procedure is based on the footing details and the field data, which can be obtained from the site investigation of a distorted house. The footing details include footing layout and footing cross-section properties (including the width and height of stiffening beams, the slab thickness, the number, size and location of steel reinforcing bars in all beams, and the details of the reinforcement mesh in the slab). The field data required includes:

- the contour plot of the measured slab deformation, preferably on a 1 to $2 \mathrm{~m}$ grid;

- a record of locations and widths of cracking in the wall, floor and ceiling;

- loadings on the soil (from building and footing construction);

- an indication of the soil profile and variation of soil reactivity with depth across the site. 
The back analysis requires a number of assumptions, the primary ones being that the concrete slab was constructed to the design and was perfectly flat to begin with.

The back analysis was carried out using a commercial finite element analysis (FEA) package namely, MSC/NASTRAN. The reinforced concrete beam was modelled with one-dimensional beam elements by defining a number of lumped bars with either concrete or steel material properties at specified distance to the neutral axis in the $x$ and $y$ directions, as illustrated in Figure 10. The reinforced concrete slab was modelled by several layers of two-dimensional plate elements, one layer being the uniaxial, distributed reinforcement layer which functions with perfect bond to the surrounding concrete, while the other layers modelled the concrete. A smeared crack model was adopted for the reinforced concrete slab. In this model, cracked concrete was treated as a continuum, that is, cracking was taken into account by modifying the material's constitutive relationship, which allowed the original discretization to be retained. The finite element model for the stiffened raft slab is shown in Figure 10.

The behaviour of concrete under multiaxial stress conditions is very complex and has not been identified completely. In this study, the concrete is assumed to be non-linear elastic and an equivalent uniaxial stress-strain relation is used. The equivalent stress $\sigma^{*}$ and strain $\varepsilon^{*}$ are defined based on the theory of energy equivalence, i.e.,

$$
\int \sigma^{*} d \varepsilon^{*}=\int\{\sigma\}^{\mathrm{T}}\{d \varepsilon\}
$$

where $\{\sigma\}$ and $\{\varepsilon\}$ are the stress and strain vectors respectively.

For a given state of $\operatorname{strain}\{\varepsilon\}^{\mathrm{T}}=\left[\varepsilon_{\mathrm{x}}, \varepsilon_{\mathrm{y}}, \varepsilon_{\mathrm{z}}, \varepsilon_{\mathrm{xy}}, \varepsilon_{\mathrm{xz}}, \varepsilon_{\mathrm{yz}}\right]$, the equivalent strain, $\varepsilon^{*}$ is computed by 


$$
\left(\varepsilon^{*}\right)^{2}=\frac{1}{\mathrm{E}}\{\varepsilon\}^{\mathrm{T}}\left[D_{\mathrm{e}}\right]\{\varepsilon\}
$$

where $\left[D_{e}\right]$ is the linear elasticity matrix, and $\mathrm{E}$ the Young's modulus.

The equivalent stress, $\sigma^{*}$ for any $\varepsilon^{*}$ is found from the stress-strain curve as shown in Figure 11. The new stress state is then determined by

$$
\{\sigma\}_{\text {new }}=1 /\left(\mathrm{E} \varepsilon^{*}\right) \sigma^{*}\left[D_{\mathrm{e}}\right]\{\varepsilon\}
$$

The compressive and tensile strength of concrete were taken as $20 \mathrm{MPa}$ and $2.7 \mathrm{MPa}$ respectively (Figure 11), based on the property of concrete used in the constructed slab. The long-term elastic modulus of concrete was $15,500 \mathrm{MPa}$ in accordance with the Australian Standard for Concrete Structures (AS3600 1994). This value of the modulus accounts for the influence of creep, shrinkage, age and loading on the modulus. The concrete density was taken as $2,400 \mathrm{~kg} / \mathrm{m}^{3}$ and a Poisson's ratio of 0.2 was adopted for the concrete.

After concrete cracks, the tensile load in the reinforced concrete footing would then be transferred to the steel reinforcement. The steel reinforcement in the beam and slab was treated as an elasto-plastic material, obeying the von Mises yield criterion and the kinematic hardening rule. Properties adopted for the reinforcing steel were a yield strength of $400 \mathrm{MPa}$, a Young's Modulus of $200 \mathrm{GPa}$ and a Poisson's ratio of 0.3 .

Although the soil foundation could be represented by a three-dimensional solid element, it was decided to use a series of one-dimensional, non-linear spring/gap elements to represent the expansive soil foundation in this case study since the initial soil suction distribution under 
the footing was unknown. This simplification removes the need to apply a constitutive model for swelling soils.

The non-linear spring/gap elements allowed for separation and relative lateral displacement between the slab and foundation soil. The behaviour of a non-linear spring/gap element with friction is path-dependent in a manner similar to plasticity. When the gap is closed, it can carry any transverse shear loads, which are less than the given coefficient of friction times the normal load. When the gap is open, there is no lateral stiffness and no frictional forces. The gap element output includes the element forces, displacements, and the gap status (i.e., open, slide, stick or slip). The shear stiffness of gap elements was determined from a modified shear box test on composite soil/concrete specimens.

When wetting up of the foundation soil occurs over part of the site, the slab will be supported mainly on the soil which has swelled, in which case the soil-footing interaction will depend on the swelling stiffness of the soil.

The swelling stiffness, $k_{s}(\mathrm{kPa} / \mathrm{m})$, is defined as

$$
k_{s}=\frac{p}{\delta-y}
$$

where $\mathrm{p}$ is the applied vertical pressure; $\delta$ is the 'free' soil swell and $\mathrm{y}$ is the soil swell under the vertical pressure, $p$.

The suppression of soil heave $(\delta$ - y) by external loads can be expressed by the spring stiffness of non-linear spring/gap elements. It represents the effective stiffness of the affected soil profile. There will be less soil-structure interaction if the stiffness is high. The swelling stiffness may be determined from the laboratory oedometer swelling tests. Figure 12 shows 
the swell-pressure relationship obtained from swell pressure tests. In such a series of tests, each specimen is allowed to swell in an oedometer under a different vertical pressure. From Figure 12 , it can be seen that the swell stiffness, $k_{s}$, depends on the vertical pressure, i.e. $k_{s}$ is not a constant.

The swell - pressure curve shown in Figure 12 can be represented by the following equation:

$$
\delta-y=\frac{1}{k_{i n i}}\left(p-a p^{t}\right)
$$

where $\delta$ is the magnitude of soil swell under no confining pressure. The curve fitting parameter $a$ and exponent $t$ can be taken as 0.0591 and 1.4098 respectively. The initial swell stiffness, $k_{\text {ini }}$, is the slope of the tangent to the swell - pressure curve at $\mathrm{y}=\delta$ (Figure 12).

Substituting Eq. (3) into Eq. (1) yields:

$$
k_{s}=k_{i n i} \frac{p}{\left(p-a p^{t}\right)}
$$

Based on the swell - pressure curve shown in Figure 12, the above equation can be used to determine the swell stiffness at a particular applied pressure, $p$. It should be noted that $k_{s}$ determined by Eq. (4) is specifically related to the height of the samples under test. The actual swell stiffness, $k_{\text {eff, }}$, of the affected soil profile in field conditions was approximated for practical purposes by

$$
k_{e f f}=k_{s} \frac{H_{o}}{H_{f}}
$$

where $H_{e}$ and $H_{e}$ are the height of oedometer ring and the depth of affected soil profile in the field respectively. 
It should be understood that the proposed method is a practical simplification of a very complex swell-pressure relationship. The swell stiffness depends on not only the vertical stresses but also the initial total suction down the profile, the extent of suction change and lateral support. Due to a lack of experimental data, a more precise definition of swelling stiffness than the approximation given by Eq. (4) was not considered in this case study.

Analyses of cracked footings resting on expansive soil profiles reported by Lytton (1970) indicated that once the tensile cracking moment has been exceeded in the slab, the footing bends easily so that it conforms very closely to the shape of the pressure-free soil surface. Therefore it is reasonable to assume that the free soil mound shape occurring under the cracked footing is similar to, but slightly larger in magnitude than the distorted shape of the footing, owing to the suppression of swelling by loading.

The first step in the back analysis procedure was to determine the measured deflection at each node of the finite element mesh. This could be done by overlaying the finite element mesh on the contour plot of the measured slab displacement. The measured vertical displacements of the slab were multiplied by a displacement factor of 1.3 and were then enforced at the underside of the spring/gap elements to represent the soil movement. The initial gap of each spring/gap was set to zero. The enforced displacement was applied in 10 equal stages in each analysis run to increase the accuracy and minimise numerical instability. It was found that the initial selected value of the displacement factor had little influence on the final results.

All calculated nodal displacements in the first finite element analysis run were compared with the measured footing displacements. The difference in the displacement was used to modify the enforced displacement values for the second analysis; the calculated spring compression 
from the previous analysis was added to the measured slab displacement to provide the estimate of the enforced displacement for the subsequent analysis. This procedure was repeated until the differences between the calculated values and the measured values were less than $2 \mathrm{~mm}$. The maximum difference could be expected to occur in an area of slab lift-off, where there is no interaction with the soil. Five iterations were required for this case study. The final enforced displacements provided an estimate of the free swell mound shape under the slab, prior to any interaction with the building and its footing.

Typical results of an iteration procedure used in this study are provided in Table 2. For simplicity, only two nodes (11 and 274, see Figure 14) are considered. A displacement factor of 1.3 was used initially. The enforced displacements were adjusted during each analysis run as previously stated by adding together the measured slab displacement and the calculated spring compression from the previous run. Using this approach the movements of the two nodes represented in Table 2, came within $1 \%$ of the measured values (see Figure 13). By the fifth analysis , the enforced displacements resulted in essentially a free swell mound shape for which further footing designs (e.g. a larger beam size, an increase in beam reinforcement or a different beam footing layout) could be analysed and tested to determine their performance when interacting with this "failure" mound shape.

The procedure adopted for the back analysis may be summarised as follows:

1) Create a finite element model consisting of steel and concrete elements;

2) Calculate the swell stiffness of the soil foundation at all nodes of finite element mesh by using Eqs. (4) and (5).

3) Determine the measured displacements at each node of the finite element mesh by overlaying the contour plot of the measured slab displacement on the mesh; 
4) Impose the measured displacements at each node from the bottom of slab, multiplied by a factor of 1.3 .

5) Perform the loaded footing-soil interaction analysis. The calculated displacements correspond to the profile of the mound having swelled under load. The calculated spring compression plus to the measured displacement gives the enforced displacement for the second finite element analysis run;

6) Step (5) is repeated until the difference between the measured displacements and the calculated displacements are acceptably small. The enforced displacements in the final run correspond to the free swell mound (i.e. free swell without suppression from the loaded footing). In other words, when this free swell mound is imposed on the slab, it would cause the measured field displacement.

7) The calculated stresses in steel and concrete from the final finite element analysis run represent the actual stress level in the deformed slab footing.

The finite element mesh for this case study is shown in Figure 14. It consisted of 608 plate elements, 196 beam elements and 348 gap elements. A line load of $6.5 \mathrm{kN} / \mathrm{m}$ was imposed along all the edges to simulate the masonry veneer walls and roof loads of the constructed building, while an internal distributed load of $2.2 \mathrm{kPa}$ was applied to model loading from internal plasterboard partitions, the floor and live loads.

\section{Results of the Back Analysis}

After five iterative analyses, the free soil mound shape (i.e. the enforced displacements in the $5^{\text {th }}$ analysis run) was determined and is shown in a three dimensional view in Figure 15. The maximum differential mound heave was found to be $120 \mathrm{~mm}$. From Figure 15, it can be seen that the foundation soils under the front and back of the house had heaved substantially more 
than the rest of the building. It should be noted that there was a ground movement monitoring station located in a flat, grassed area, approximately $800 \mathrm{~m}$ away from this cracked building. The seasonal ground movement measured by Cameron (the second author of this paper) was 28 mm (Cameron 1989; Fityus et al. 2005). The predicted soil mound shape clearly shows that a leaking underground water pipe and excessive garden watering can cause more severe distortion to the footing than the seasonal climate influence and the normal environmental changes to the site caused by the imposition of the building on a greenfield site.

It needs to be pointed out that the site classification (Class E) prior to construction was based on the visual-tactile method, while $28 \mathrm{~mm}$ was the seasonal ground movement measured over a one-year period at a ground movement monitoring station located in the same suburb. Site classification takes into account the expected normal environmental changes brought about by development of a building block and in Adelaide a depth of 4 metres is considered appropriate, over twice the depth of seasonal effects.

The back-analysis provided an estimate of the level of stress in the distressed slab footing. It was predicted that the footing was over-stressed at the re-entrant corner, B (see Figure 13). The calculated maximum torque and bending moment in the external beams in this region were $80 \mathrm{kNm}$ and $399 \mathrm{kNm}$, respectively. The maximum shear force was $142 \mathrm{kN}$. The maximum compressive stress in the concrete was found to be $13 \mathrm{MPa}$, which was acceptable. The results of the back analysis indicated that the maximum tensile stress of $2.7 \mathrm{MPa}$ in the concrete beams had been exceeded and that the steel bars at the bottom of the beam along section I-I should have yielded (see Figure 13). So this section of the slab had failed in a structural sense. The back analysis predicted concrete cracking in both edge and internal 
beams at the locations indicated on Figure 13, close to the location of the observed superstructure cracks (refer Figures 2-5).

Having the free swell mound derived from the 'as-constructed' analysis, footing designers may ask what kind of footing would be required for the given field conditions and beam layout shown in Figure 1. In other words, when this new slab footing with a larger beam size is superimposed on to the free swell mound as shown in Figure 15, the calculated slab differential deflections would be less than the maximum allowable limit specified in AS2870.

Revised beam depths were analysed for the 'as-constructed' beam layout. The depth of all stiffening beams was increased from $950 \mathrm{~mm}$ (the 'as-constructed' depth) to $1200 \mathrm{~mm}, 1500$ $\mathrm{mm}$ and $1800 \mathrm{~mm}$ respectively. The numerical results indicated that a $1500 \mathrm{~mm}$ deep beam was satisfactory for the imposed free swell mound (Figure 15) by AS2870. The contour plot of the calculated slab deflections is shown in Figure 16. The maximum values as presented below were obtained.

- deflection ratio

- compressive stress in concrete

- bending moment in beam

- torque in beam

- shear force in beam

$$
=1 / 1060
$$$$
=7.5 \mathrm{MPa}
$$$$
=910 \mathrm{kN} \mathrm{m}
$$$$
=78 \mathrm{kN} \mathrm{m}
$$$$
=220 \mathrm{kN}
$$

The maximum differential deflection and the maximum compressive stress in the concrete were all reduced significantly, when compared to the 'as constructed' footing. As would be expected, the moments and shear forces were both increased with the increased beam depth. However the maximum torque was almost unchanged. Although this stronger footing could 
not eliminate cracking of concrete beams, the number of overstressed beam elements was greatly reduced when compared with the as-constructed footing. Cracking of beams is not a major concern as conventional footing design accepts partially cracked concrete sections.

The back-analysis results indicated that a $1500 \mathrm{~mm}$ deep stiffening beam was required for the slab to be able to withstand the differential soil movement induced by abnormal soil wetting from leaking pipes and excessive watering. As such deep beams are outside the scope of the shallow footing designs intended in AS2870 and are not a practical solution, the case study has demonstrated the importance of site management for buildings on expansive soil sites, with the aim of maintaining a reasonably uniform state of subsoil moisture around the buildings.

\section{CONCLUSIONS}

In this study, the field investigation and back analysis of a cracked residential house were carried out. Field investigations revealed that the major cause of house distortion could be attributed to service pipe leaks across the site and excessive garden watering, which resulted in non-uniform soil moisture conditions. In terms of AS2870, the site could not be considered a "normal site" as it has been subjected to abnormal moisture conditions.

The method of back analysis proposed in this study allowed a detailed three-dimensional investigation to be made of a distressed slab. The results of the back analysis indicated that stresses at the re-entrant corner were most critical and steel reinforcing bars in the beams had yielded along the re-entrant corner line. A much stronger footing would have been required for interaction with the free swell soil mound shape derived from the back analysis. This 
analysis demonstrated the potential additional costs to homeowners if designers were to try and design for extreme events and therefore the need for homeowners to continue to maintain site conditions to a reasonable level.

The revised beam depth obtained from the AS2870 recommended design approach (twodimensional) was much larger than that suggested by the three-dimensional analysis method adopted in this research. It appears that the current design approach was over conservative when applied to this particular case.

The case study has clearly shown that a leaking underground water pipe or/and excessive lawn watering could cause more severe distortion to the footing than the expected moisture changes due to seasonal influences and re-distribution of soil moisture arising from construction on the site. It is believed that case studies such as the one presented in this paper can lead to a higher level of understanding of the performance of footings on expansive soils and subsequently reduce the risk in routine footing design.

\section{REFERENCES}

AS 1289.7.1.1 (1992), "Methods for Testing Soils for Engineering Purposes: Method 7.1.1:

Determination of the Shrinkage Index of a Soil; Shrink Swell Index”, Standards Australia.

AS 1289.2.2.1 (1992), "Methods of Testing Soil for Engineering Purposes, Soil Moisture Content Tests, Determination of Total Suction of a Soil”, Standards Australia.

AS 2870 (2011), "Residential slab and footings", Standards Australia.

AS 3600 (1994), “Concrete structures”, Standards Australia.

Cameron, D.A. and Walsh, P. F. (1981), "Inspection and Treatment of Residential Foundation Failures”, First National Local Government Engineering Conference, Adelaide, 186-191. 
Cameron, D.A., Walsh, P.F. and Richards, B. G. (1987), “Australian Approach to the Problem of Expansive Soils", Proc. 9th Regional Conf. for Africa on Soil Mechanics and Foundation Eng., Lagos, 977-989.

Cameron, D.A. (1989), “Tests for Reactivity and Prediction of Ground Movement", Civil Engineering Transaction, IE Aust., 31(3), 121-132.

Considine, M. (1984), "Soils shrink, trees drink, and houses crack”, ECOS Magazine 41, 1315.

Delaney, M.G., Li, J. and Fityus, S.G. (2005), "Field Monitoring of Expansive Soil Behaviour in the Newcastle-Hunter Region", Journal of Australian Geomechanics, 6(2), 3-14.

Fityus, S.G., Smith, D.W. and Allman, M.A. (2004), “An expansive soil test site near Newcastle", ASCE Journal of Geotechnical and Geoenvironmental Engineering, 130(7), 686-695.

Fityus, S. G., Cameron, D. A. \& Walsh, P. F. (2005), “The shrink swell test”, Geotechnical Testing Journal, 28, 92-101

Jaksa, M. B., Cavagnaro, R. L. and Cameron, D. A. (1997). "Uncertainty Associated with the Visual-Tactile Method for Quantifying the Reactivity of Expansive Soils". Australian Geomechanics, No. 31, pp. 84-91.

Jones, L. D., and Jefferson, I. (2012), “Expansive soils”, ICE Publishing, 413-441

Li, J. (2006), “Two Dimensional Simulation of a Stiffened Slab on Expansive Soil subject to a Leaking Underground Water Pipe", Unsaturated Soils. Geotechnical Special Publication No. 147, G. Miller, C. Zapata, S. Houston and D. Fredlund, eds., ASCE, Arizona, 20982109

Li, J. and Cameron, D. A. (2002), “A case study of a courtyard house damaged by expansive soils”, Journal of Performance of Constructed Facilities ASCE, 6, 169-175. 
Lytton, R.L. (1970), "Design Criteria for Residential Slabs and Grillage Rafts on Reactive Clay", Report for CSIRO, Division of Applied Geomechanics, Melbourne, Australia.

Miao, L., Wang F., Cui, Y. and Shi, S.B. (2012), "Hydraulic characteristics, strength of cyclic wetting-drying and constitutive model of expansive soils", Proc. 4th Int. Conf. on Problematic Soils, Wuhan, China, 303-322.

The AGE (2011). "Owners find homes are cracking under pressure", Viewed 11 February 2013 at http://theage.domain.com.au/home-owning-tips/owners-find-homes-are-crackingunder-pressure-20111221-1p5or.html

Walsh, P. F., and Cameron, D. A. (1997), "The design of residential slabs and footings", Standards Australia, SAA HB28-1997 
Table 1: Site Classification Classes to AS2870 (2011)

\begin{tabular}{|c|c|l|}
\hline $\mathrm{y}_{\mathrm{s}}(\mathrm{mm})$ & Class & \multicolumn{1}{|c|}{ Description } \\
\hline $0<\mathrm{y}_{\mathrm{s}} \leq 20$ & $\mathrm{~S}$ & slightly reactive \\
$20<\mathrm{y}_{\mathrm{s}} \leq 40$ & $\mathrm{M}$ & moderately reactive \\
$40<\mathrm{y}_{\mathrm{s}} \leq 60$ & H1 & highly reactive \\
$60<\mathrm{y}_{\mathrm{s}} \leq 75$ & H2 & highly reactive \\
$\mathrm{y}_{\mathrm{s}}>75$ & E & extremely reactive \\
\hline
\end{tabular}


Table 2: Typical Results of an Iteration Procedure (all values in mm)

\begin{tabular}{|c|c|c|c|}
\hline Node Number & 11 & 274 & \\
\hline Measured Displacement & 55 & 63 & \\
\hline Enforced Displacement & $71.5(=1.3 \times 55)$ & $81.9(=1.3 \times 63)$ & \multirow{5}{*}{$\begin{array}{c}\text { First } \\
\text { Analysis }\end{array}$} \\
\hline Displacement Factor & 1.30 & 1.30 & \\
\hline Calculated Displacement & 46.5 & 66.9 & \\
\hline Error & $8.5(=55-46.5)$ & $-3.9(=63-66.9)$ & \\
\hline Spring Compression & $25(=71.5-46.5)$ & $15(=81.9-66.9)$ & \\
\hline Enforced Displacement & $80(=55+25)$ & $78(=63+15)$ & \multirow{5}{*}{$\begin{array}{c}\text { Second } \\
\text { Analysis }\end{array}$} \\
\hline Displacement Factor & 1.45 & 1.24 & \\
\hline Calculated Displacement & 52.4 & 61.1 & \\
\hline Error & $2.6(=55-52.4)$ & $1.9(=63-61.1)$ & \\
\hline Spring Compression & $27.6(=80-52.4)$ & $16.9(=78-61.1)$ & \\
\hline Enforced Displacement & $82.6(=27.6+55)$ & $79.9(=63+16.9)$ & \multirow{5}{*}{$\begin{array}{c}\text { Third } \\
\text { Analysis }\end{array}$} \\
\hline Displacement Factor & 1.50 & 1.27 & \\
\hline Calculated Displacement & 54.3 & 61.2 & \\
\hline Error & $0.7(=55-54.3)$ & $1.8(=63-61.2)$ & \\
\hline Spring Compression & $28.3(=82.6-54.3)$ & $18.7(=79.9-61.2)$ & \\
\hline Enforced Displacement & $83.3(=55+28.3)$ & $81.7 \quad \ldots$ & \multirow{5}{*}{$\begin{array}{c}\text { Fourth } \\
\text { Analysis }\end{array}$} \\
\hline Displacement Factor & 1.51 & 1.30 & \\
\hline Calculated Displacement & 54.5 & 63.3 & \\
\hline Error & $0.5(=55-54.5)$ & $-0.3(=63-63.3)$ & \\
\hline Spring Compression & $28.8(=83.3-54.5)$ & $18.4(=81.7-63.3)$ & \\
\hline Enforced Displacement & $83.8(=55+28.8)$ & 81.5 & \multirow{5}{*}{$\begin{array}{c}\text { Fifth } \\
\text { Analysis }\end{array}$} \\
\hline Displacement Factor & 1.52 & 1.29 & \\
\hline Calculated Displacement & 54.8 & 62.8 & \\
\hline Error & $0.2(=55-54.8)$ & $0.2(=63-62.8)$ & \\
\hline Spring Compression & $29(=83.8-54.8)$ & $18.7(=81.5-62.8)$ & \\
\hline
\end{tabular}




\section{Figure Captions}

Figure 1 Footing Layout and Locations of Underground Pipe Leak (not to scale)

Figure 2 Crack on Ceiling in Family Area

Figure 3 Crack on the Interior Wall between Dining Room and Lounge

Figure 4 Crack in Brick Wall under Window of Bedroom 2

Figure 5 Distortion of Cornice in Laundry Area

Figure 6 Geotecnical Profile at BH1

Figure 7 Measured Relative Slab Deflection (mm)

Figure 8 Measured Level Differences along the Re-entrant Corner

Figure 9 Soil Suction Profiles

Figure 10 Finite Element Model for Stiffened Raft Slab

Figure 11 Pressure - swell Curve obtained from Oedometer Swelling Tests

Figure 12 The Stress-Strain Curve of Concrete

Figure 13 Difference between measured slab displacement and displacement of slab from the back analysis

Figure 14 Finite Element Mesh and Locations of Concrete Beam Cracking

Figure 15 Free Swelling Mound Shape - 3D View (mm)

Figure 16 Contour Plot of the Calculated Slab Deflections for Beam Depth $=1500 \mathrm{~mm}(\mathrm{~mm})$ 


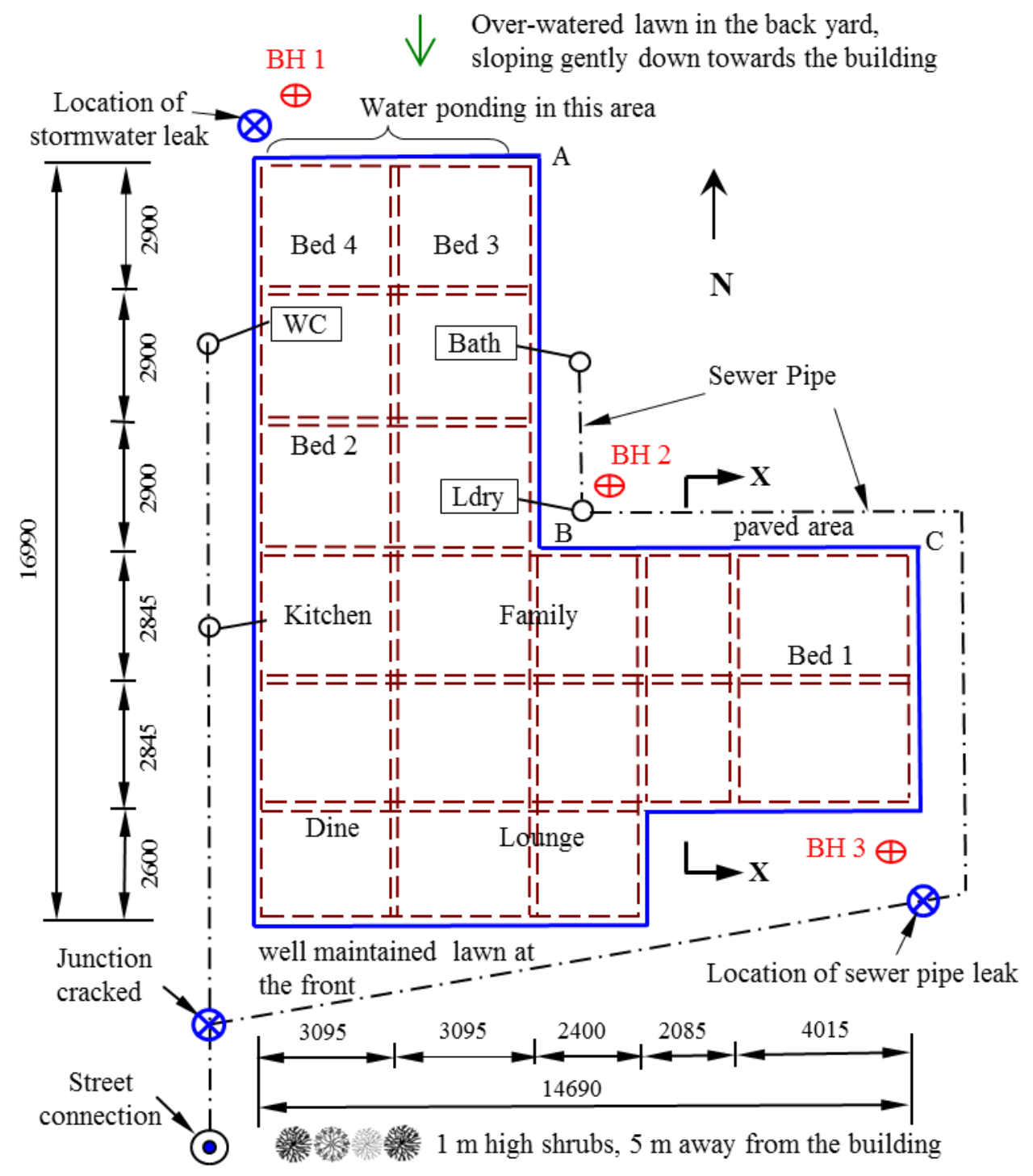

(a) Plan Layout

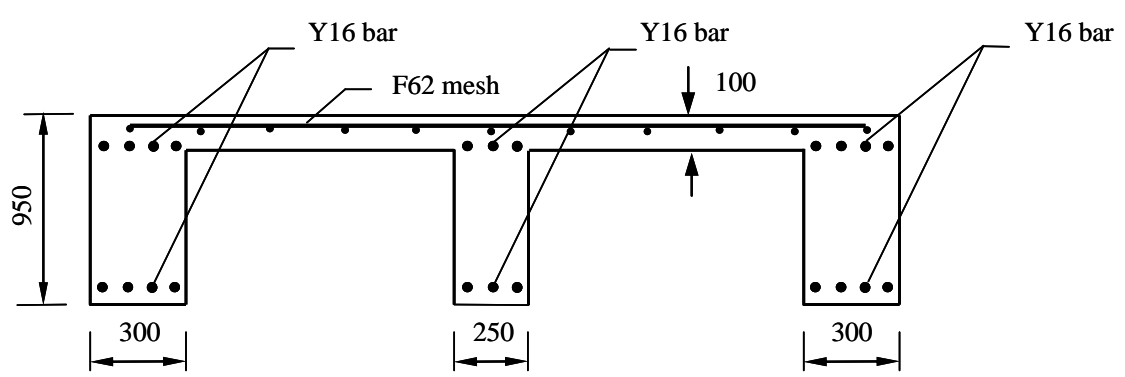

(b) Section X-X

Figure 1 Footing Layout and Locations of Underground Pipe Leak (not to scale) 


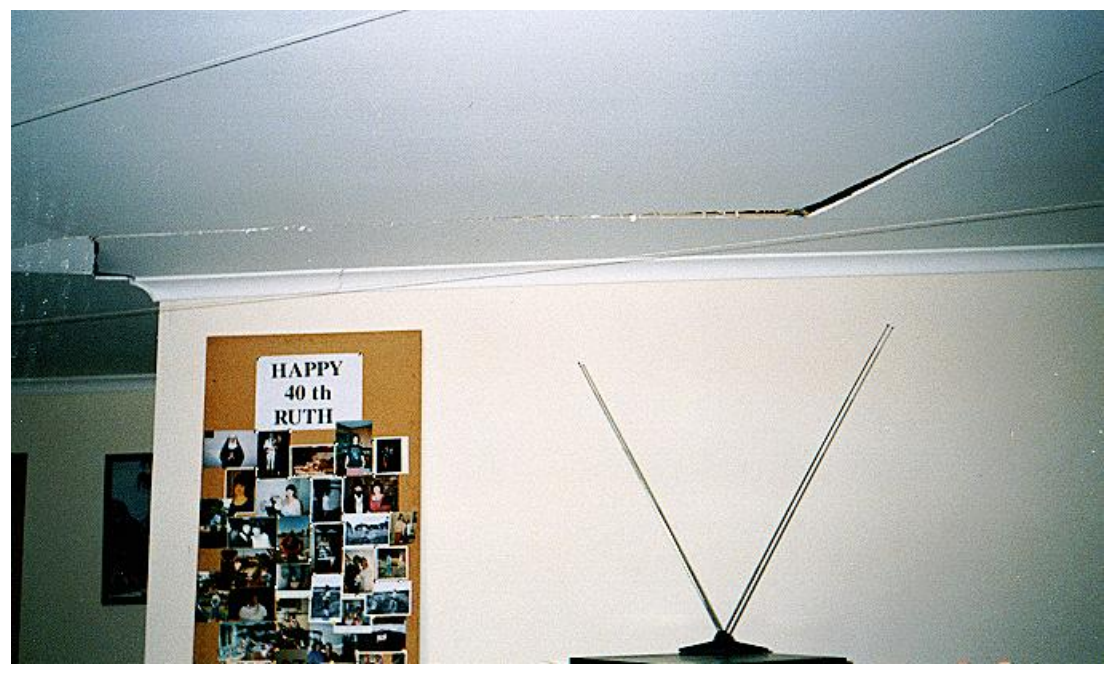

Figure 2 Crack on Ceiling in Family Area 


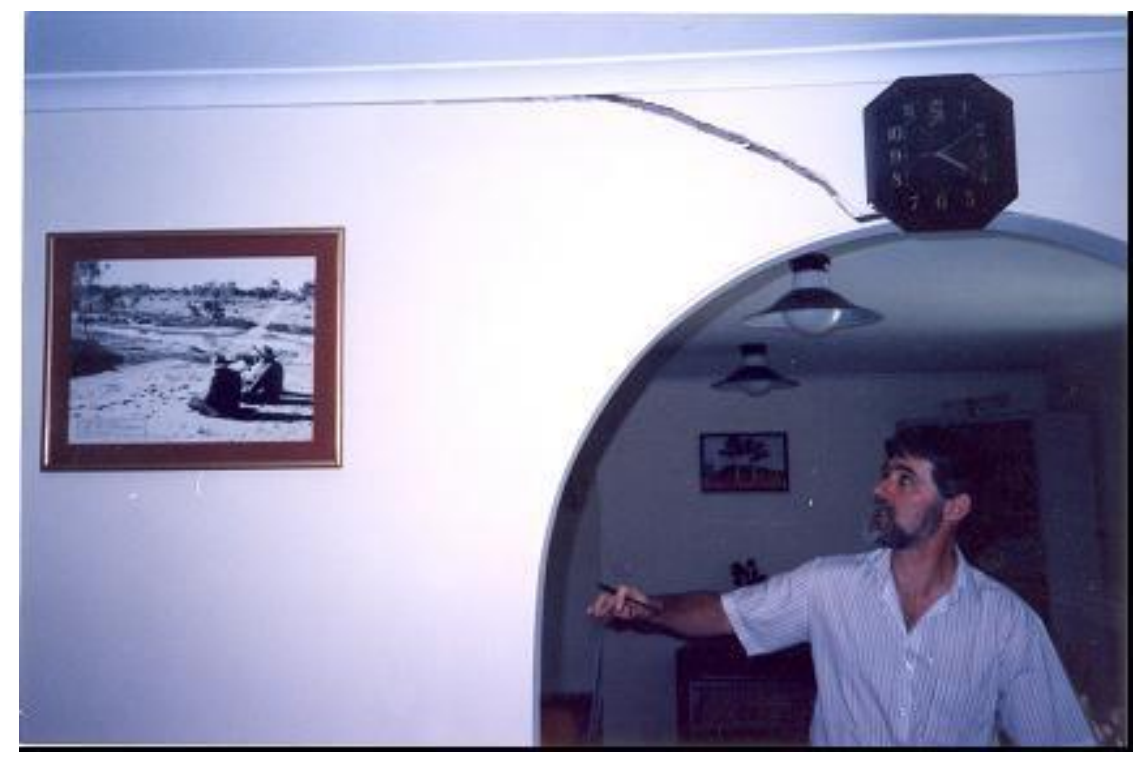

Figure 3 Crack on the Interior Wall between Dining Room and Lounge 


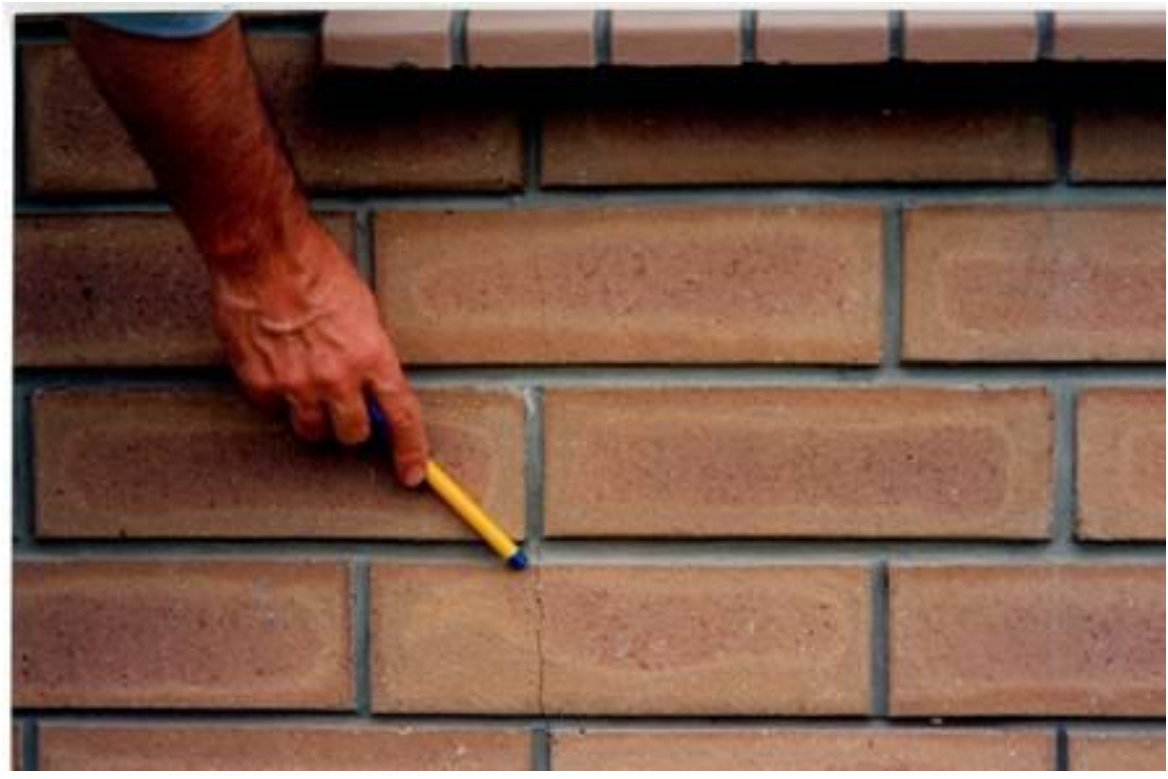

Figure 4 Crack in Brick Wall under Window of Bedroom 2 


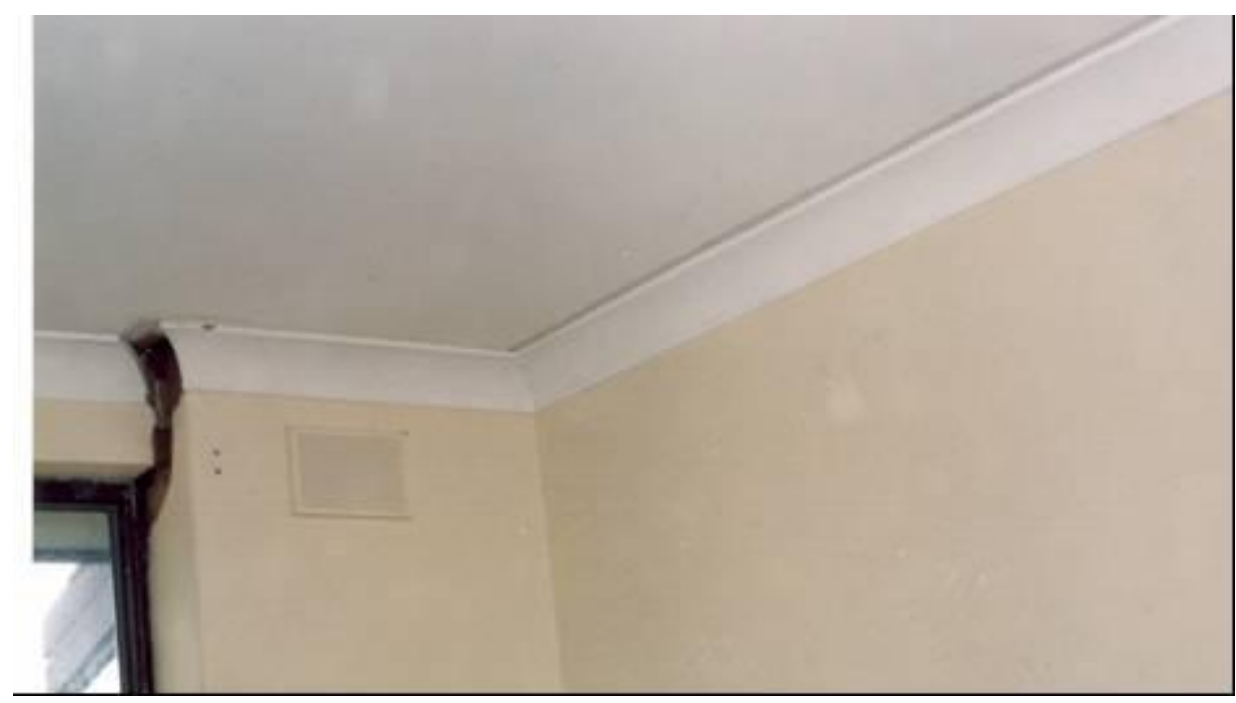

Figure 5 Distortion of Cornice in Laundry Area 

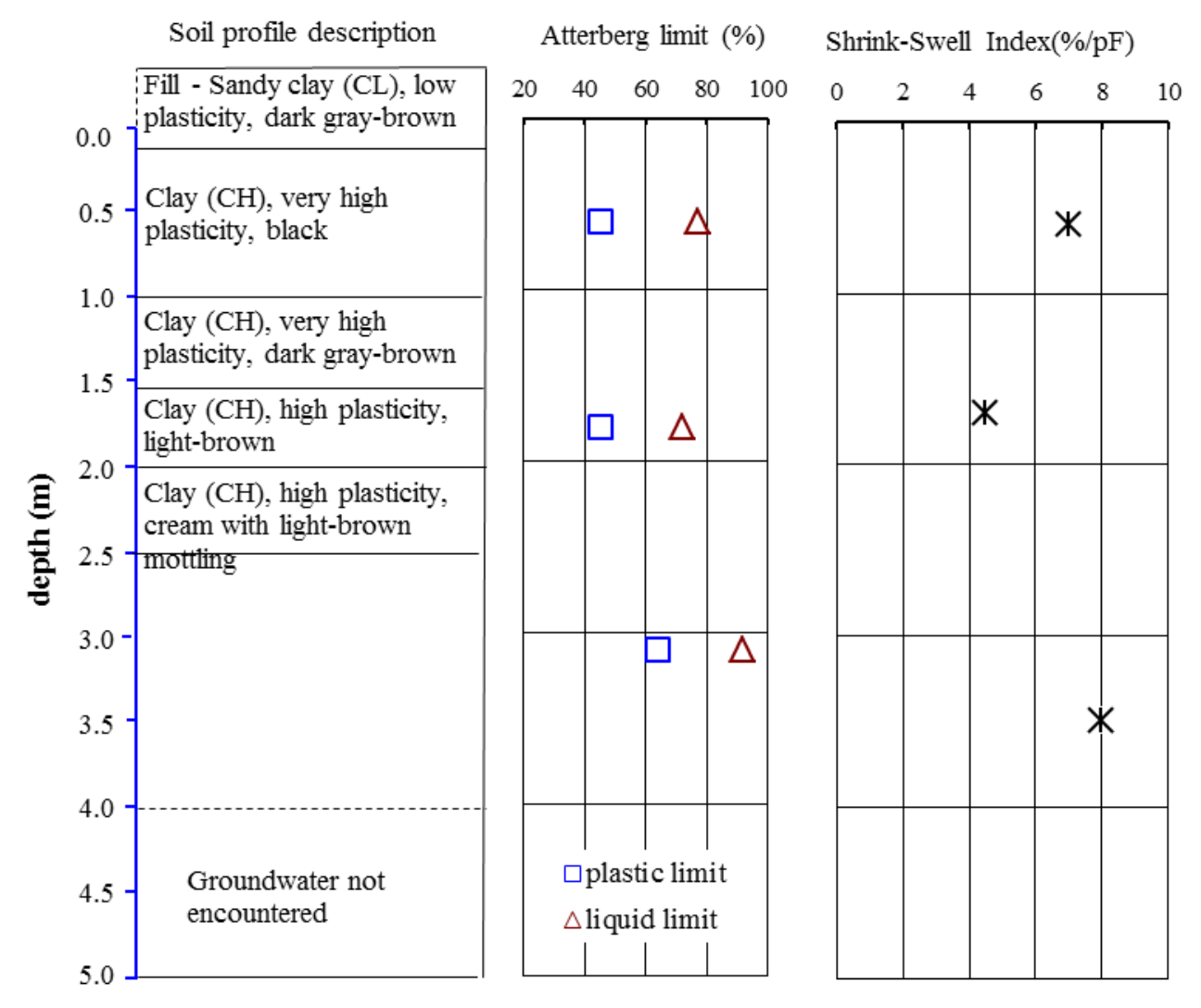

$0 \quad 200 \quad 400 \quad 600$
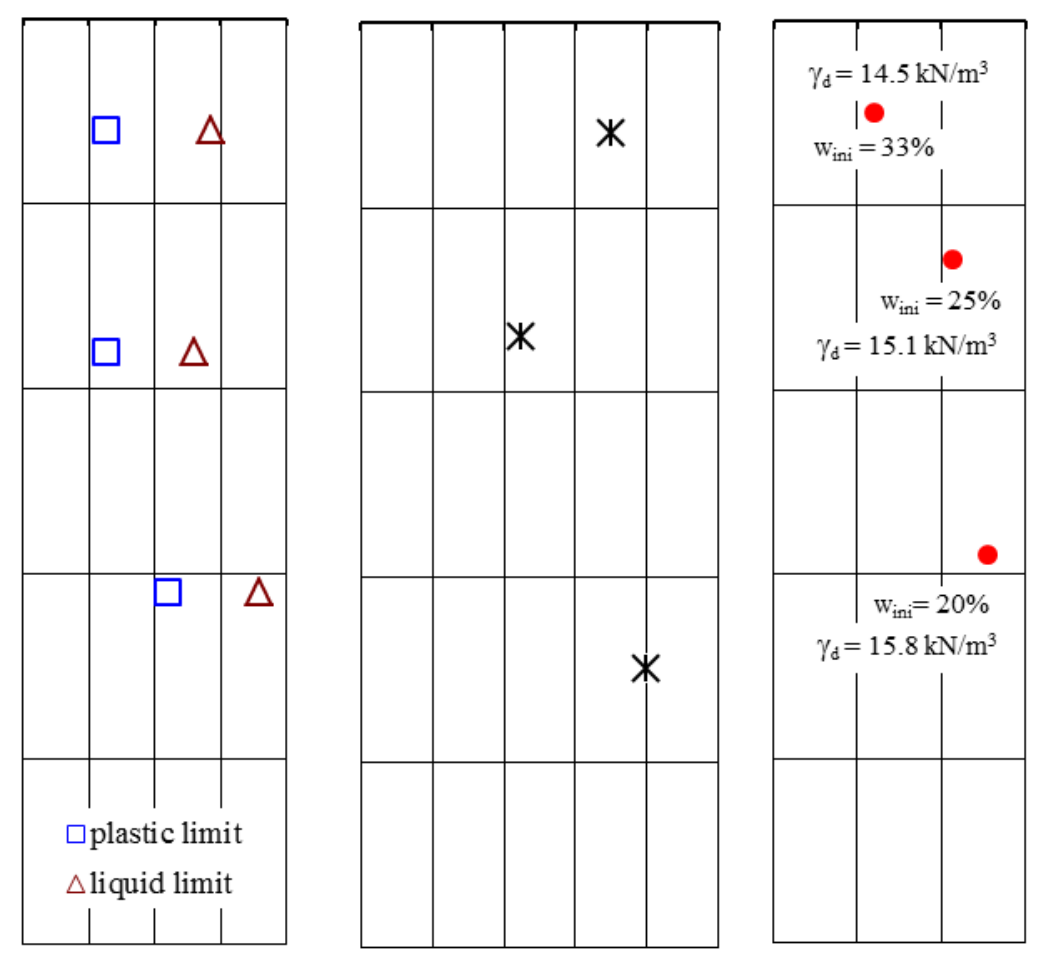

Figure 6 Geotechnical Profile at BH1 


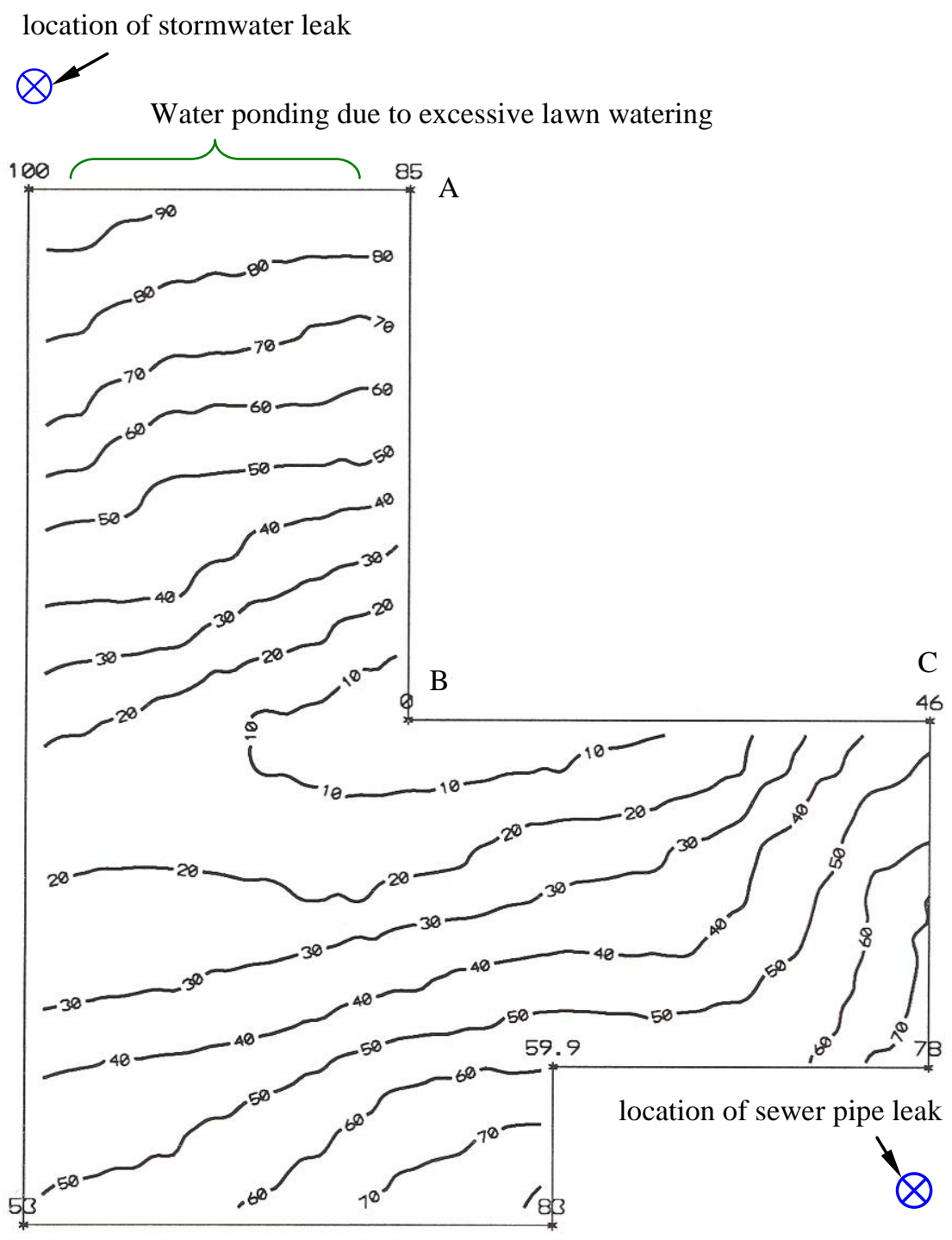

Figure 7 Measured Relative Slab Deflection (mm) 


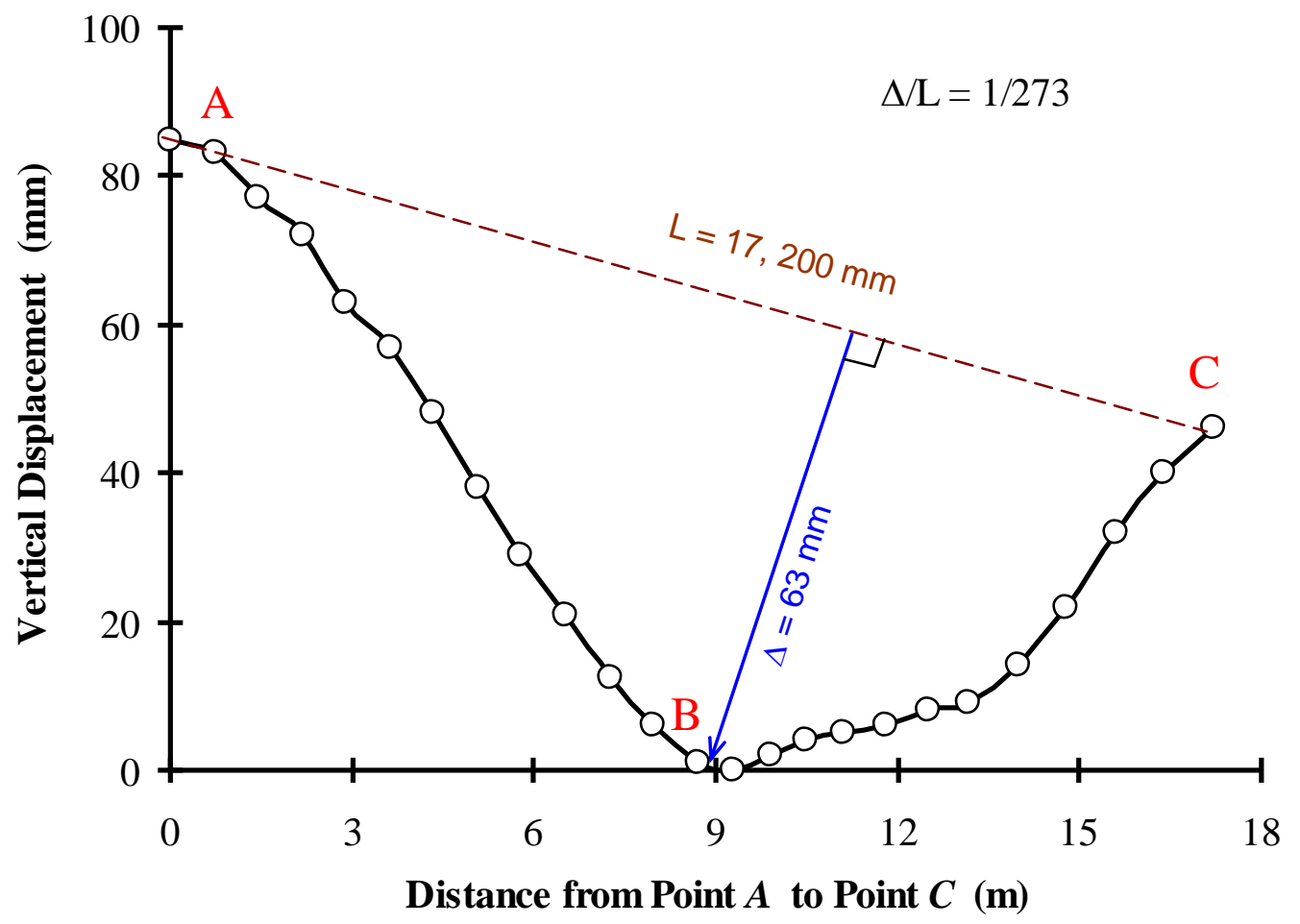

Figure 8 Measured Level Differences along the Re-entrant Corner 


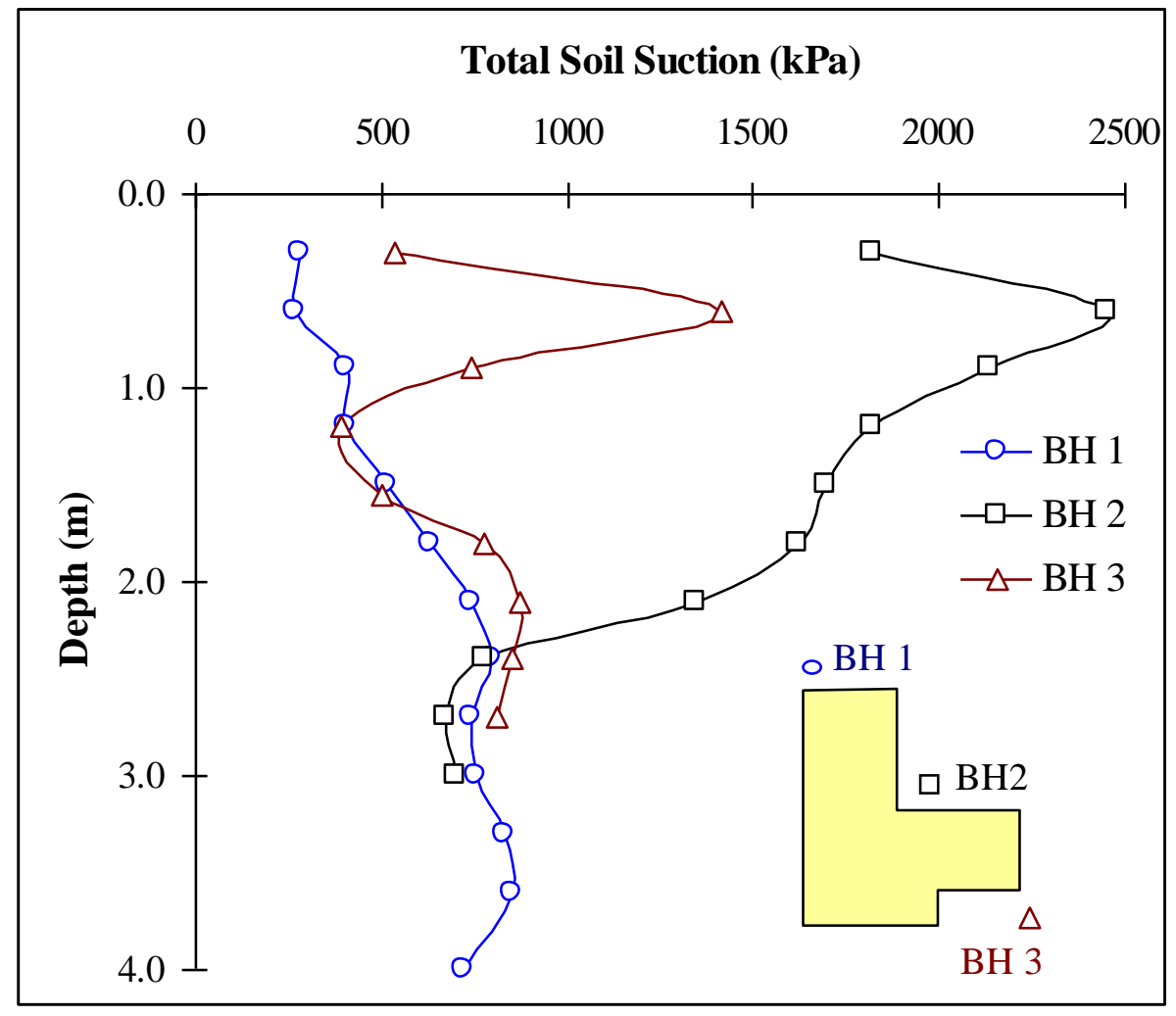

Figure 9 Soil Suction Profiles 


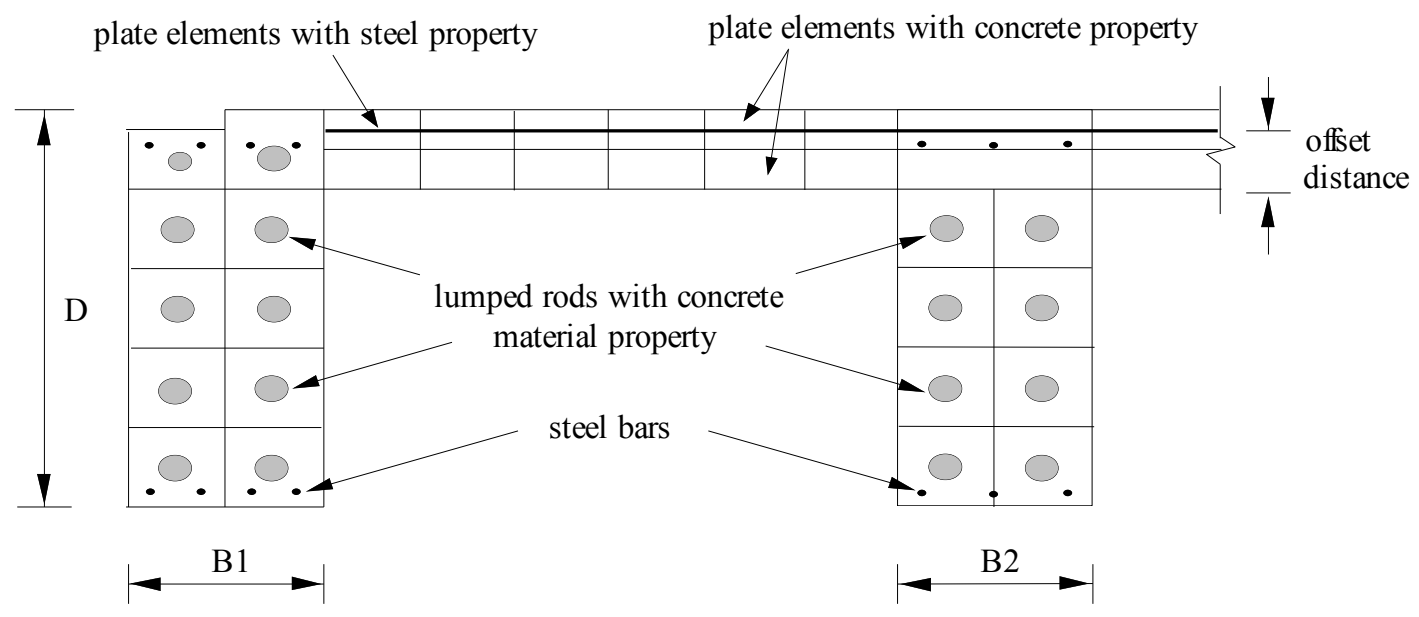

Figure 10 Finite Element Model for Stiffened Raft Slab 


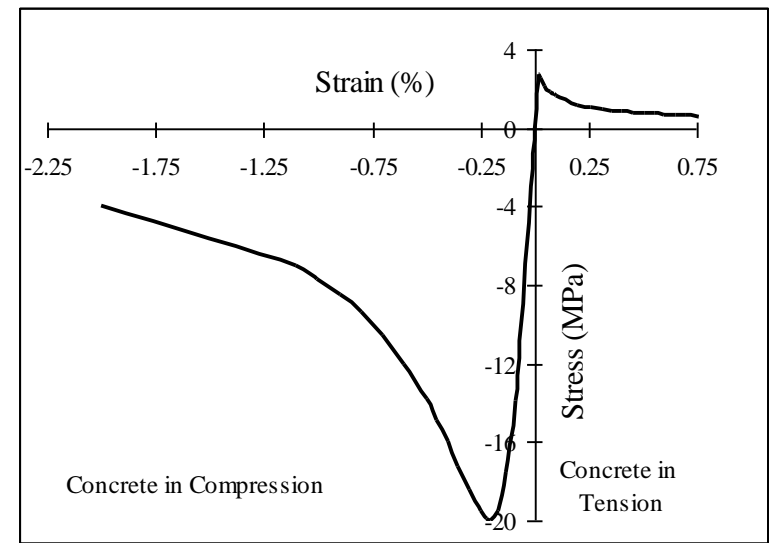

Figure 11 The Stress-Strain Curve of Concrete 


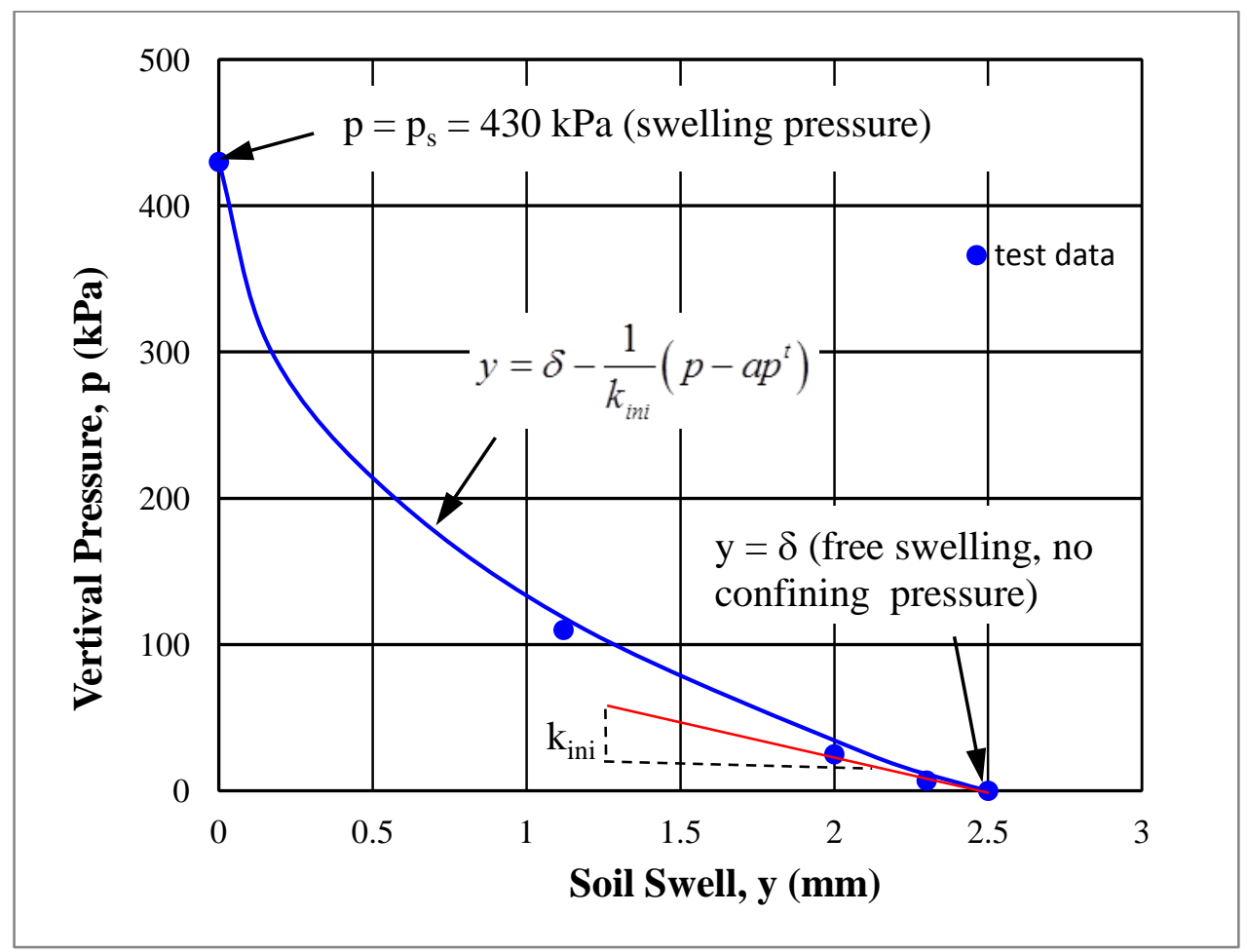

Figure 12 Pressure - swell Curve obtained from Oedometer Swelling Tests (initial total suction $=4.2 \mathrm{pF}$ ) 

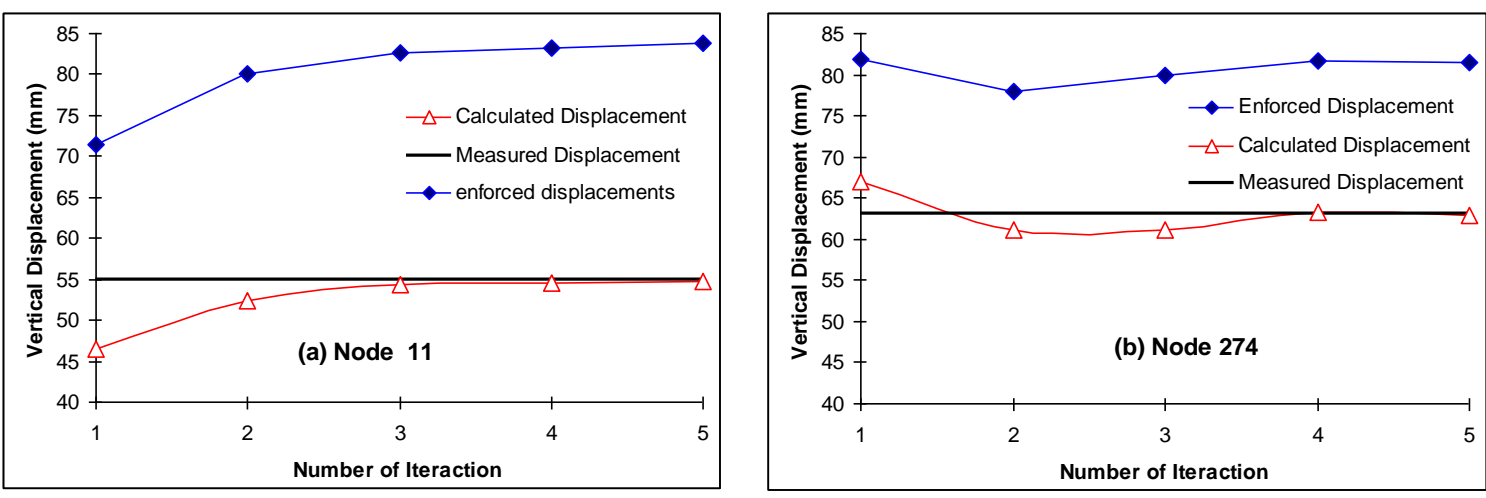

Figure 13 Difference between measured slab displacement and displacement of slab

from the back analysis (the locations of nodes 11 and 274 are indicated in Figure 13) 


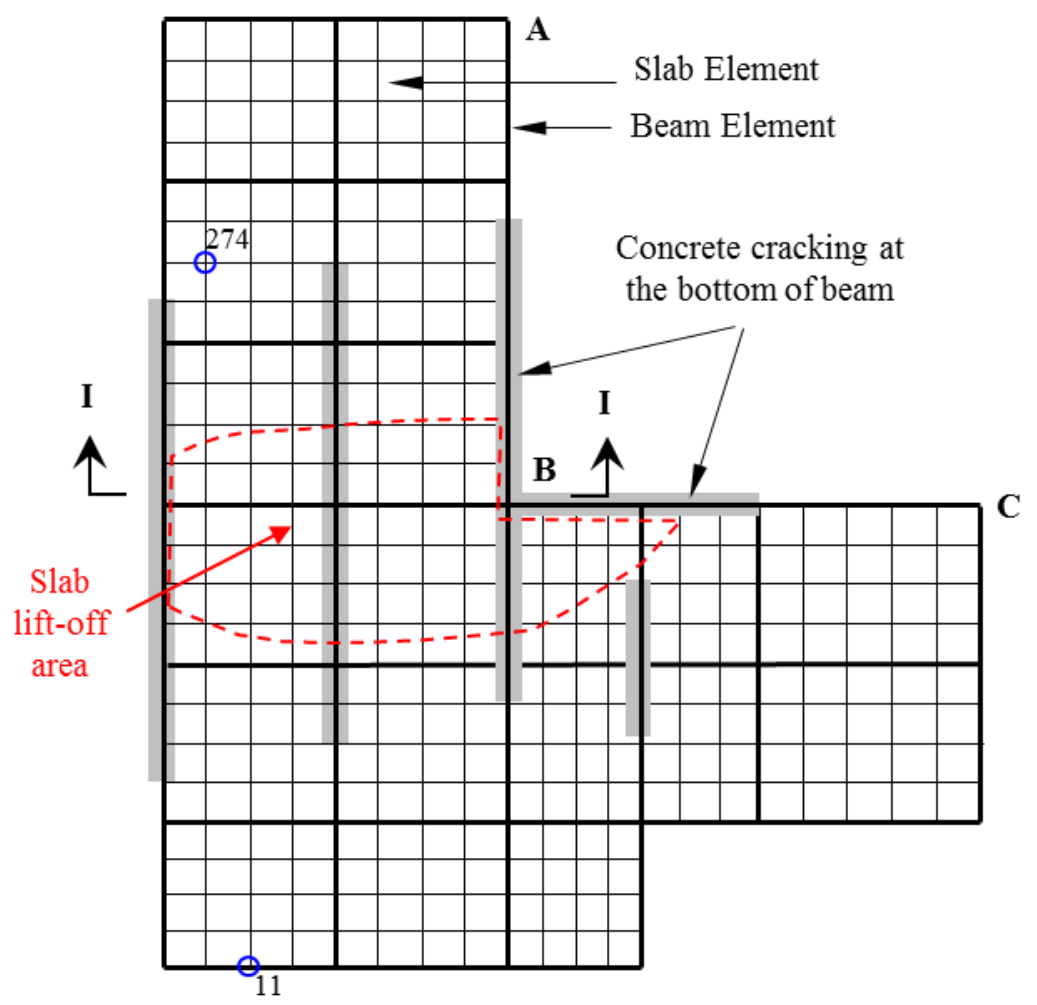

Figure 14 Finite Element Mesh and Locations of Concrete Beam Cracking 


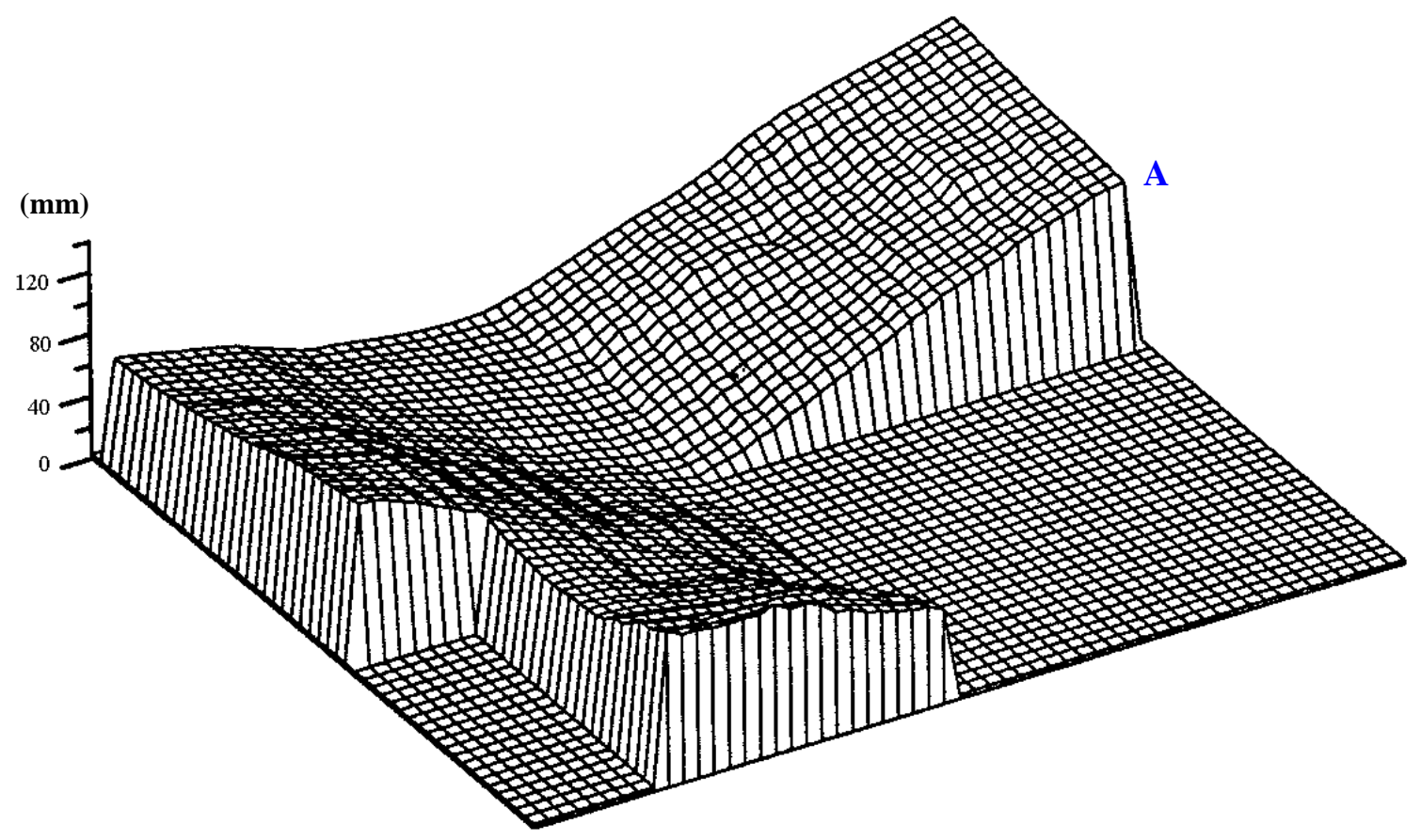

Figure 15 Free Swelling Mound Shape - 3D View (mm) 


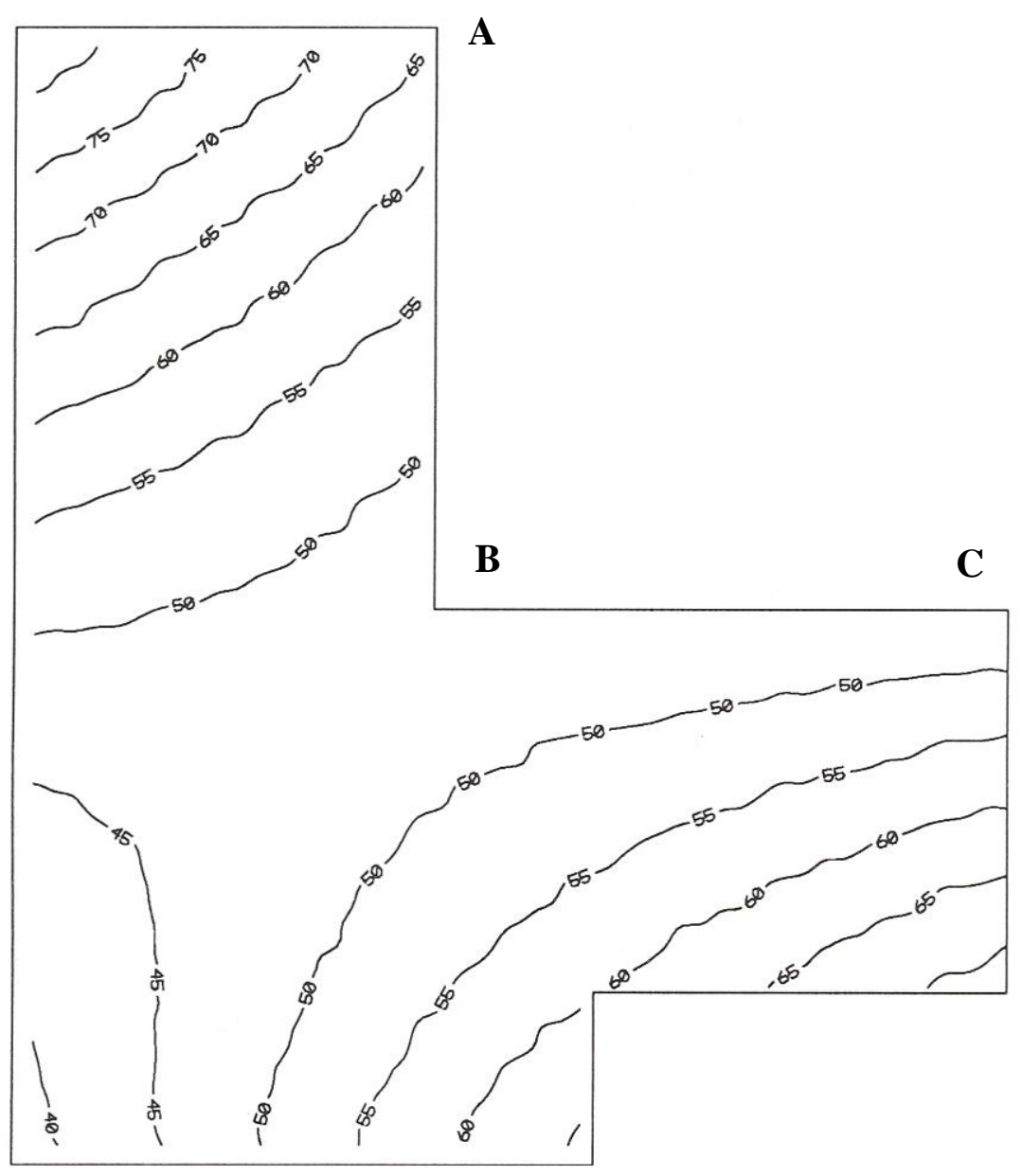

Figure 16 Contour Plot of the Calculated Slab Deflections for Beam Depth $=\mathbf{1 5 0 0} \mathbf{m m}$ (mm) 